\title{
A fundação da primeira sociedade brasileira especializada em medicina mental
}

\author{
The first Brazilian society specialized in mental medicine
}

\author{
EDE C. B. CEROUEIRA \\ Casa de Oswaldo Cruz | Fiocruz
}

\begin{abstract}
RESUMO A Sociedade Brasileira de Neurologia, Psiquiatria e Medicina Legal foi criada em 1907, na cidade do Rio de Janeiro, por um grupo de médicos interessados no desenvolvimento destas especialidades. Neste artigo procuro analisar o contexto em que tal instituição de caráter médico e cientifico foi fundada, observando os elementos que contribuíram para sua criação e sua relevância para a comunidade médica local.
\end{abstract}

Palavras chave história - instituições - psiquiatria - neurologia - medicina legal.

\begin{abstract}
The Brazilian Society of Neurology, Psychiatry and Forensic Medicine (SBNPML) was created in 1907, in the city of Rio de Janeiro, for a group of physicians that was looking for the development of these specialties. In this article, I want to analyze the context of this medical and scientific institution's foundation, noticing the elements that contributed to its creation and its relevance to the local medical community.
\end{abstract}

Keywords history - institutions - psychiatry - neurology - forensic medicine.

\section{Introdução}

Durante um longo tempo, as produções historiográficas interessadas no estudo da institucionalização das ciências no Brasil privilegiaram como temas de pesquisa a criação dos institutos e universidades que apareceram ao longo do século XX, assim como a implantação das disciplinas científicas, marginalizando o papel desempenhado pelas associações neste processo. ${ }^{1}$ Neste contexto, o estudo da história das instituições não abrangia as questões presentes no cotidiano destas entidades, sendo apresentados apenas os resultados produzidos naqueles ambientes, enquanto contribuições à ciência. ${ }^{2}$ Porém, a partir dos anos 1980 e 1990, pesquisadores produziram estudos detalhados sobre importantes instituições científicas brasileiras dos séculos XIX e XX, partindo da crítica ao anacronismo, até então presente na historiografia brasileira, e procurando trabalhar com os critérios de cientificidade do período estudado. ${ }^{3}$ Neste viés de análise, as academias e sociedades passaram a ser observadas enquanto objetos de pesquisa sobre a constituição de espaços de produção de ciência no Brasil, considerando que a análise da arquitetura interna destas associações pode apontar para concepções científicas em voga e em disputa, de maneira a demonstrar que ideias científicas e sua materialidade institucional são inextricavelmente dependentes. ${ }^{4}$ 
Partindo desta última concepção teórica, neste artigo ${ }^{5}$ procuro analisar o contexto em que a Sociedade Brasileira de Neurologia, Psiquiatria e Medicina Legal (SBNPML) foi fundada, em 17 de novembro de 1907, por um grupo de médicos, na cidade do Rio de Janeiro, então capital da República. Tal agremiação, desde sua criação, era apresentada por seus fundadores como uma instituição de caráter médico e científico, cujos principais objetivos eram a difusão dos ramos do conhecimento médico que a nomeavam e o incentivo ao desenvolvimento das instituições de assistência aos alienados, tanto no Distrito Federal como em outros estados brasileiros.

No geral, poucos são os trabalhos historiográficos que tratam sobre a história da SBNPML. Os principais tratam preferencialmente da estrutura geral da entidade ${ }^{6}$ ou focalizam a relevância do periódico Arquivos Brasileiros, enquanto uma fonte de referência para estudos sobre psiquiatria, ${ }^{7}$ o que nos levou a procurar analisar de forma mais detalhada a história desta agremiação, ${ }^{8}$ focalizando neste texto 0 momento de sua fundação, com interesse em observar os seguintes aspectos da sua constituição: os elementos que corroboraram para a criação desta instituição; a relevância desta para seus fundadores e primeiro grupo de associados; e as relações estabelecidas, dentro da agremiação, entre as áreas da medicina que a nomeavam, neste período inicial.

Para analisar a constituiç̧ão do grupo de associados da SBNPML utilizo o conceito de gerações entre intelectuais, ${ }^{9}$ compreendendo elementos como idade e ano de conclusão dos estudos, não como fatores estanques, mas como indicadores fundamentais para a identificação de ideias políticas e intelectuais compartilhadas, assim como de fases da trajetória profissional dos médicos. Também procuro identificar a existência de possíveis estruturas de solidariedades no sentido de interesses culturais compartilhados, visto que as gerações não podem ser consideradas como naturais e atemporais, considerando que "um intelectual se define sempre por referência a uma herança", seja como continuador de um legado ou como alguém que rompe com a tradição. ${ }^{10}$

\section{Modernizar, sanear, embelezar: o contexto de fundação da SBNPML}

A fundação da SBNPML ocorreu em um período marcado por grandes obras de saneamento e remodelação da capital federal, iniciadas sob a presidência de Rodrigues Alves e a gestão municipal de Pereira Passos, entre 1902 e 1906. Neste contexto, as obras urbanísticas desenvolvidas entre 1903 e 1906, o período do "bota abaixo 11", tinham o intuito de transformar a capital da República em uma cidade "moderna, higiênica e civilizada" tal qual as metrópoles europeias, norte-americanas e a vizinha Buenos Aires. Para os reformadores era imprescindível sanear para sanar problemas da urbe, tais como as epidemias de febre amarela e varíola, que, dentre outras, assolavam a cidade constantemente, 0 que levava esta a ser rotulada como "cidade insalubre, empesteada e miasmática", o que prejudicava bastante as suas relações comerciais com o mercado internacional. ${ }^{12}$

Assim, os planos de remodelação urbana incluíam a modernização do porto, abertura de amplas avenidas, alargamento e retificação de ruas de modo que facilitassem o trânsito e a circulação do ar, criação de parques e praças, aterro de mangues e charcos, canalização de rios e córregos, criando uma nova arquitetura principalmente para o centro comercial e político da cidade. Entretanto, tais reformas, se por um lado favoreceram a alguns proprietários de casas ou comércios que foram indenizados pelo Estado ou conseguiram manter seus imóveis ainda mais valorizados pelas obras, por outro lado expurgaram uma parcela muito maior da população pobre de suas habitações e locais de trabalho, com a demolição de muitos cortiços e outros prédios considerados insalubres do centro. Isto intensificou os problemas já existentes de falta de moradia, superpovoamento e insalubridade dos domicílios entre as camadas trabalhadoras da população carioca, e ainda levou ao aumento dos aluguéis e da especulação imobiliária. ${ }^{13}$ Estes foram alguns dos fatores que colaboraram para a eclosão de revoltas populares no período. ${ }^{14}$

Contudo, passado o período de agitações mais agudas, o ano de 1907 representava para o governo federal, já sob a presidência de Afonso Pena, e para a parcela da elite carioca que havia lucrado com as reformas, o início de um período de grande entusiasmo, com a construção de obras suntuosas ao longo da Avenida Central (atual Av. Rio 
Branco) - a principal obra da administração de Pereira Passos - e com a preparação para a Exposição Nacional, que ocorreria naquela capital no ano seguinte.

A Exposição Nacional de 1908, a sétima realizada no Rio de Janeiro, representava uma pré-seleção entre os estados brasileiros dos produtos e invenções que representariam o Brasil em mais uma das Exposições Universais. ${ }^{15}$ Estas foram iniciadas na metade do século XIX, com o objetivo de apresentar os "progressos" em áreas diversas como agricultura, indústria, ciência e artes de cada país às demais nações e ao mesmo tempo estreitar laços de comércio e intercâmbio cultural entre os participantes. Porém, elas também serviam ao propósito de comparar e hierarquizar as nações em "modernas" ou "atrasadas" e os povos em "civilizados" ou "bárbaros", seguindo critérios evolucionistas e progressistas. ${ }^{16}$

Realizada em 1908, como comemoração ao centenário da abertura dos portos, a Exposição Nacional demandou a construção de suntuosos pavilhões para a exposição de cada estado, todos localizados na região da Praia VermeIha, atual bairro da Urca. Esta foi a forma encontrada pelo governo brasileiro e pela elite carioca de expor a capital, parcialmente reformada, como uma vitrine dos projetos de "modernidade" e "civilização" pretendidos para o país, e ao mesmo tempo fazer um inventário da produção nacional. ${ }^{17}$ As obras de arquitetura e engenharia empreendidas na Capital Federal entre 1903-1906 eram apresentadas como um cartão postal da "moderna" república brasileira, mesmo que a realidade dos sertões brasileiro demonstrasse 0 contrário. ${ }^{18}$

Assim, a SBNPML foi criada em um momento em que germinavam, entre a elite política e intelectual da capital da República, ideias sobre a possibilidade do país superar, por meio do investimento em saúde e educação da população, 0 destino de atraso e degeneração para 0 qual as teorias deterministas do século XIX o predestinavam, para então alçar voo rumo ao "progresso". Até aquele momento, as principais teorias defendidas no debate sobre construção da identidade nacional, que marcou o final do século XIX e início do XX, estavam baseadas no pensamento de Gobineau, Agassiz e Le Bon, que viam a questão racial como um dos principais obstáculos ao desenvolvimento da nação brasileira, que só podia ser superado pela intensa imigração e consequente branqueamento da população. ${ }^{19}$

Em 1905, dois anos antes da criação da Sociedade, o médico e escritor Manoel Bomfim (1868-1932) ${ }^{20}$ questio-

nava, em sua análise sobre o desenvolvimento das nações sul-americanas, se estariam estas, e em especial o Brasil, fadadas à eterna desorganização e ao atraso decorrente de uma suposta inferioridade étnica, ou de elementos de sua história que as impediriam de alcançarem a civilização. Como resposta, Bomfim definia as teorias baseadas no determinismo racial como "pseudocientíficas" e "insubsistentes", uma vez que para ele, o que faltava a esses povos era 0 desenvolvimento da "cultura moral e intelectual", que só poderia ser conseguido pela educação. ${ }^{21}$

Apesar da intelectualidade da época defender projetos que investissem em educação e saúde, principalmente a partir de 1910 e das campanhas de saneamento do sertão em 1916, ${ }^{22}$ isto não significava que as benesses destes projetos chegassem ao alcance da maior parte da população. 0 que acontecia, mais especificamente no caso do Distrito Federal, era que os projetos defendidos pelos administradores públicos, assim como por seus consultores engenheiros, médicos, educadores e juristas, apontavam para a necessidade de higienizar a cidade, erradicar os surtos epidêmicos e normatizar os hábitos da população, o que acabava por empurrar para os morros e periferias da cidade uma parcela significativa da população trabalhadora e pobre, cada vez mais excluída.

Este contexto político e intelectual era propício para a criação de novas instituições de caráter científico que buscassem fornecer respostas para o que eram vistos como problemas da nação. E a medicina foi uma das áreas do conhecimento que procurou apresentar estas respostas, pelas vias do experimentalismo e da especialização do perfil médico.

\section{Experimentar, especializar e prevenir: os novos saberes sobre a doença}

A medicina acadêmica brasileira presenciou intensos debates acerca dos fundamentos epistemológicos do saber médico e em prol de uma nova noção de medicina baseada no experimentalismo, nas últimas três décadas do século 
XIX. Entre a geração de médicos mais jovens, estavam aqueles que defendiam amplamente a medicina experimental, assim como a aproximação da medicina brasileira com a produzida em centros científicos europeus, como a Alemanha, por exemplo. Assim, em 1879, iniciou-se uma ampla reforma do ensino médico brasileiro seguindo o modelo germânico, em prol do desenvolvimento da pesquisa científica, do ensino prático e da especialização das diversas áreas da medicina. Concomitantemente, ampliava-se o movimento em defesa do perfil do médico como "detentor de um saber especializado" e da "crença inabalável no poder preventivo e curativo da medicina 'científica'". 23

Nas primeiras décadas do século XX ampliou-se o movimento de especialização das áreas do conhecimento, inclusive do desdobramento da medicina em áreas específicas de acordo com a patologia ou parte do corpo a ser tratada. Para que os cientistas e intelectuais modernos pudessem diferenciar-se dos ultrapassados enciclopédicos era fundamental a valorização de sua capacidade de ação e intervenção na realidade, assim como da racionalidade, da especialização das atividades e funções, da técnica e da divisão social do trabalho. Pois, ao mesmo tempo que as novas tecnologias de comunicação e transporte reduziam distâncias, alterando a antiga noção de tempo e espaço e proporcionando um sentimento de urgência frente à velocidade dos novos tempos, estas mudanças abalavam "o antigo padrão de produção intelectual, até então assentado na ideia de uma formação longa e completa de estudos e num modelo de um saber enciclopédico". ${ }^{4}$

Porém, um outro modelo de medicina mais antigo e menos especializado ainda estava presente na comunidade médica brasileira. Neste, o médico percebia o corpo do paciente como uma unidade e o adoecimento como um desequilíbrio das funções vitais. Segundo este modelo, o perfil do médico deveria estar baseado no amplo conhecimento sobre os males que afligem o físico, o moral e o mental do indivíduo e como tratá-los em sua totalidade. ${ }^{25}$

0 movimento em prol da especialização médica convivia com elementos deste modelo mais amplo de fazer medicina e ser médico, preocupado com o todo ao invés das partes, uma vez que o perfil do médico brasileiro passava por um período de transição do generalista para o especialista. Assim, não era incomum encontrar médicos que estavam se aperfeiçoando em uma área determinada da medicina, como a psiquiatria, a neurologia ou a pediatria, e que simultaneamente participavam de diferentes associações médicas, científicas e culturais. ${ }^{26}$ Além disso, o especialista médico e o cientista conviviam com o "erudito" versado em letras, artes e política, em alguns casos não só reunindo os diferentes perfis em um mesmo grupo, mas até mesmo como faces de um mesmo indivíduo. ${ }^{27}$

A tendência à especialização que esteve presente nas várias áreas do conhecimento científico, sobretudo nas áreas médicas, foi reforçada pelo aparecimento de formas de trabalho referentes a parcelas cada vez mais restritas da totalidade do processo de diagnóstico e terapêutica. Desta maneira, o surgimento de novas especialidades clínicas, relacionadas a determinadas patologias, áreas específicas do corpo humano ou faixas etárias, esteve diretamente ligado às mudanças no modelo de formação e prática médica. ${ }^{28}$

Neste período, a psiquiatria e a neurologia estavam em processo de constituição e institucionalização enquanto especialidades do saber médico, em relação à medicina legal, área de estudo mais antiga. Este foi um momento de demarcação de fronteiras entre estas áreas quanto ao seu objeto de estudo, ao estabelecimento de elementos que as definissem enquanto especialidades autônomas - como a criação de cadeiras independentes nas faculdades de medicina -, à institucionalização de espaços de estudo e trabalho separados, à delimitação das áreas do conhecimento médico sobre as "doenças mentais e moléstias nervosas" que caberiam a cada uma das especialidades e à elaboração de textos de divulgação e manuais.

Teixeira Brandão (1854-1921)29, em texto do final do século XIX, aponta que a psiquiatria, neste período, estava intrinsecamente ligada à medicina legal. Segundo ele, esta matéria médica tinha como objetivo interceder junto à Justiça para que indivíduos que tivessem cometido "atos criminosos promovidos pela insânia" não fossem condenados, por serem considerados incapazes de responder por suas ações; e, em segundo lugar, corrigir junto ao enfermo "as aberrações intelectuais restituindo a inteligência e o equilíbrio" dos indivíduos..$^{30}$

Na Faculdade de Medicina do Rio de Janeiro ocorreu inicialmente a distinção entre medicina legal e psiquiatria e, posteriormente, a especificação da neurologia em relação à mesma psiquiatria. A cadeira de medicina legal foi criada com 
a reforma do ensino superior de 1832, que transformou as escolas de medicina da Bahia e Rio de Janeiro em faculdades de medicina. ${ }^{31} 0$ estudo das "doenças mentais e moléstias nervosas" fazia parte de suas atribuições até 1883, quando efetivamente passou a funcionar a cadeira de psiquiatria. ${ }^{32}$ Esta última foi criada pelo decreto 8.024, de 1881, em um contexto de reforma do ensino médico em prol das especialidades, quando também foram instituídas as cadeiras de oftalmologia, moléstias cutâneas e sifilíticas, clínica médica das crianças, fisiologia patológica e patologia experimental. ${ }^{33}$

Por outro lado, a neurologia no Brasil esteve estritamente ligada à psiquiatria até as primeiras décadas do século $X X$, sendo o primeiro livro brasileiro dedicado inteiramente ao estudo das moléstias do sistema nervoso publicado em 1878, por João Vicente Torres Homem, com o título Lições sobre as moléstias do sistema nervoso feitas na Faculdade de Medicina do Rio de Janeiro. ${ }^{34}$ Somente em 1912, o estudo das moléstias nervosas foi desvinculado da cadeira de psiquiatria e surgiu a cadeira de doenças do sistema nervoso na FMRJ, também denominada de clínica neurológica. Naquela ocasião, Antonio Austregesilo (1876-1961)35 foi escolhido, pela congregação da faculdade, como primeiro professor da nova cadeira. ${ }^{36}$

Neste contexto, a psiquiatria, dentre outras novas especialidades da medicina, passava por um processo de institucionalização e demarcação do seu espaço de atuação. Por um lado, ela procurava se constituir como área separada da medicina legal em seu objeto de estudo, ao mesmo tempo em que ainda mantinha fronteiras muito fluidas com a neurologia. Assim, a SBNPML foi a primeira sociedade brasileira criada com a intenção de especializar-se no estudo das "doenças mentais e moléstias nervosas". Esta instituição seguia um movimento mais amplo da psiquiatria, que buscava entender e explicar as manifestações classificadas de tal forma, assim como controlar seus efeitos e portadores, procurando determinar formas de "prevenção" e "tratamento" para acometimentos físicos e morais.

\section{Sociedades científicas e agremiações especializadas}

As academias e sociedades brasileiras, entre os séculos XVI e XVIII, representaram as principais formas de agrupamento científico, sendo, inicialmente, "compostas pelos interessados em trabalhar em prol do movimento científico", tornando-se, ao final do século XVII, organizações do tipo profissional, e, ao final do século XIX, restritas aos especialistas. Elas tinham como intuito "estimular os indivíduos a realizar pesquisas, recompensá-los pelos êxitos obtidos e facilitar a comunicação das atividades científicas", sobretudo com a publicação de periódicos que divulgavam resultados e críticas. $^{37}$

A fundação de sociedades científicas respondia a diversos propósitos, como a necessidade das nações latino-americanas recém-independentes de conhecer seu próprio território, e também o desenvolvimento de áreas de interesse dos cientistas desses países, apresentando um forte "caráter utilitarista", expresso no intuito de modernizar cada país. Assim, as sociedades converteram-se num espaço de institucionalização da ciência, assessorando os governos em várias matérias, além de divulgarem o ideário cientificista e, principalmente, estimularem os debates científicos. Também funcionavam, muitas vezes, como um grupo de pressão em relação tanto à "comunidade" científica quanto ao poder político local. ${ }^{38}$

A ciência brasileira produzida entre o século XIX e as primeiras décadas do XX apresentava "a ligação entre a atividade científica e o trabalho profissional, enquanto práticas inseparáveis", de maneira que o "exercício profissional da medicina representou uma das poucas alternativas disponíveis para os indivíduos interessados em ciência". ${ }^{39}$ Neste mesmo contexto, a criação de sociedades científicas específicas convergiu com o movimento de institucionalização das cátedras universitárias cada vez mais especializadas. Entretanto, a criação de cátedras nas universidades não deve ser compreendida como o início do processo de especialização dos saberes, mas como o reconhecimento da sua importância na produção científica brasileira. ${ }^{40}$

Consideramos que a institucionalização das ciências no Brasil, entre o final do Império e início da República, incluiu não apenas as instituições voltadas para o ensino formal, como universidades, mas as variadas formas de implantação 
de práticas e conhecimentos científicos por meio de periódicos, sociedades cientificas, instituições de pesquisa e laboratórios. Assim, podemos pensar a criação de sociedades médicas específicas, como a SBNPML e a Sociedade Brasileira de Pediatria ${ }^{41}$ como um movimento no sentido de institucionalizar e divulgar determinados saberes e também como forma de agregar os médicos interessados em um novo perfil profissional, que envolvia em maior ou menor escala ser médico especialista, cientista e intelectual. ${ }^{42}$ Desta forma, podemos encontrar médicos que participavam ao mesmo tempo de sociedades especializadas como a SBNPML e a Sociedade Brasileira de Dermatologia; ${ }^{43}$ de instituições que reuniam todas as áreas médicas, como a Academia Nacional de Medicina e a Sociedade Brasileira de Medicina e Cirurgia, e de outras agremiações de intelectuais, como a Sociedade Brasileira de Ciências, a Academia Brasileira de Letras e o Instituto Histórico e Geográfico Brasileiro.

Entretanto, o interesse de muitos médicos em serem aceitos como sócios destas entidades não correspondia à participação efetiva destes no cotidiano destas instituições. A prática de criar novas agremiações ou a intensa procura por filiar-se a estas convivia com o esvaziamento das reuniões, a centralização da sua gestão entre poucos membros e o desaparecimento prematuro de muitas delas, devido à falta de participação da maior parte de seus sócios e à falta de recursos. Para alguns médicos, principalmente os iniciantes na profissão, tornar-se sócio destas instituições dava status, legitimava a prática daquele médico perante seus pares e a comunidade leiga, dando-lhe acesso à elite médica local, ao mesmo tempo que servia como passaporte para o seleto mercado de trabalho, que, no caso da medicina mental, era formado principalmente por cargos públicos. Outra forma de estabelecer o associativismo entre os médicos se deu por meio da colaboração em periódicos médicos. Estes, além de divulgar o discurso médico, representavam um espaço para o debate de temas controversos e em alguns casos também de vulgarização do conhecimento científico para o público leigo.

No caso específico da SBNPML, esta surge como herdeira da reunião de um grupo de médicos que colaboravam na publicação do periódico Arquivos Brasileiros de Psiquiatria, Neurologia e Ciências Afins, ${ }^{44}$ criado em 1905, por Juliano Moreira (1873-1933), ${ }^{45}$ diretor do Hospício Nacional de Alienados (HNA), e Afranio Peixoto (1876-1947), ${ }^{46}$ alienista da mesma instituição. 0 periódico foi criado em cumprimento do novo regulamento da assistência, em vigor desde 0 ano anterior, que determinava que o diretor do hospício deveria "encarregar-se dos estudos e pesquisas que interessarem a psiquiatria e ás moléstias nervosas, publicando esses trabalhos, conforme os meios orçamentários de que dispuser a Assistência para ocorrer a despesa". ${ }^{77}$

No período de 1905 a 1919, o periódico esteve diretamente ligado ao HNA, sendo impresso e encadernado nas oficinas tipográficas deste, e custeado por verba específica da Assistência. Após a fundação da Sociedade, em 1907, o periódico tornou-se seu órgão de divulgação oficial, publicando um resumo das atas de reunião desta. Entretanto, 0 periódico também mantinha outras seções, como: matérias (composta por artigos e comunicação de estudos desenvolvidos pelos membros da Sociedade e outros colaboradores da revista), bibliografia (onde eram feitos comentários sobre algumas obras), notícias, cartas, necrológios, publicações recebidas, versas (que traziam poemas de pacientes) e análises (com comentários sobre artigos publicados em periódicos médicos brasileiros e de outros países). ${ }^{48}$

Desde 1908, os editores da revista eram escolhidos entre os membros da Sociedade, geralmente integrantes da diretoria, o que foi oficializado em 1914, quando foi deliberado em reunião da SBNPML que os Arquivos Brasileiros seriam anualmente confiados a uma comissão de redação eleita pelos sócios da agremiação e composta por três destes. Porém, apesar do periódico Arquivos Brasileiros ter funcionado durante os primeiros 24 anos de sua existência como órgão oficial de divulgação da Sociedade (1908-1918; 1919-1931), este não era propriedade desta instituição. ${ }^{49}$

\section{A criação da SBNPML e seus membros fundadores}

A história da SBNPML que foi contada por seus membros ao longo das primeiras décadas do século XX e registrada nas páginas do seu órgão de divulgação oficial, o periódico Arquivos Brasileiros de Psiquiatria, Neurologia e Medicina 
Legal, começou no chuvoso domingo de 17 de novembro de 1907, no salão da Academia Nacional de Medicina, no Rio de Janeiro, onde um grupo de médicos "cultores das especialidades" de psiquiatria, neurologia e medicina legal reuniu-se e "deliberaram fundar a referida sociedade". 50

Esta versão do ato de fundação da Sociedade foi publicada em nota curta do seu periódico, atrelando a criação da instituição a uma das entidades científicas mais prestigiadas pela comunidade médica do período - a Academia Nacional de Medicina (ANM). Ao final da nota, são listados os nomes dos médicos que participaram da reunião e daqueles que aderiram à Sociedade logo após a sessão, constituindo o grupo de sócios fundadores, formado, em sua maioria, por médicos já bem conceituados na capital, como Azevedo Sodré51 (1863-1929), Teixeira Brandão, Souza

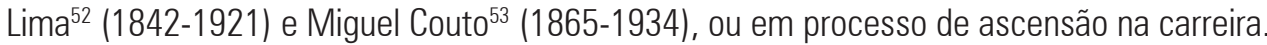

A partir de 1916, a fundação da Sociedade foi rememorada nos discursos de comemoração de seu aniversário - inicialmente por seu presidente Juliano Moreira e depois pelos demais membros da instituição -, sendo a cada ano revestida de maior importância, ao ponto de ser incluída, pelo mesmo Juliano Moreira, entre os marcos formadores da história da psiquiatria no Brasil. ${ }^{54}$ Da mesma maneira, passados 48 anos de sua criação, a história da agremiação contada pelo seu presidente Heitor Peres, em seu discurso de posse, retomava a narrativa do momento de fundação da Sociedade, ${ }^{55}$ revestida de grandiosidade.

Tais discursos sobre a história da instituição, em geral, buscavam demonstrar sua relevância para a comunidade médica e científica especializada, tanto nacional como internacional, ${ }^{56}$ procurando manter viva a memória dos "pais fundadores" da instituição, ou pelo menos de alguns deles, e ressaltando a longevidade da Sociedade enquanto uma instituição médica especializada em relação a outras no panorama nacional e internacional que, segundo Juliano Moreira, "não vingavam" por muito tempo.

Como não foi possível localizar a ata da reunião em que a Sociedade foi criada, realizamos aqui uma comparação da nota publicada nos Arquivos Brasileiros, que, como vimos, concentrava-se em anunciar a fundação da nova instituição, com uma pequena notícia veiculada por um jornal de São Paulo - o Correio Paulistano ${ }^{57}$-, que traz uma versão diferente do ato de criação da Sociedade. Este jornal, no exemplar de 18/11/1907, informava sobre uma reunião que teria acontecido no dia anterior, no Rio de Janeiro, convocada pela comissão executiva do IV Congresso Médico Latino-Americano, ${ }^{58} \mathrm{com} 0$ objetivo de discutir questões referentes ao evento mencionado. ${ }^{59}$ De acordo com a notícia, a pauta da reunião tratava da aprovação de dezesseis artigos dos estatutos do congresso médico e também de outras deliberações cujo intuito era preparar o Distrito Federal para ser a sede do evento. Assim, ao final daquela reunião, ficou decidido enviar ao presidente da República uma petição para que fosse construído um novo edifício para a Faculdade de Medicina e outra solicitação para o ministro do Interior, para que fossem proporcionados os meios para que "o congresso desempenhasse cabalmente sua missão". E, por fim, foi deliberada a fundação de uma sociedade de psiquiatria, neurologia e medicina legal.

Comparando a nota publicada nos Arquivos Brasileiros, já mencionada, com a notícia do jornal Correio Paulistano, percebemos que, ao contrário da ideia implícita na nota do periódico da SBNPML, aquela reunião não foi convocada apenas com o intuito de fundar tal sociedade, e que os médicos já renomados, como também os iniciantes que compareceram àquela sessão, ${ }^{60}$ estavam mobilizados por um objetivo mais amplo - a preparação para o IV Congresso Médico Latino-Americano.

Todos os fundadores da SBNPML eram médicos, totalizando o número de trinta e um ${ }^{61}$ que estiveram presentes à reunião em que a agremiação foi criada, somados a outros onze ${ }^{62}$ que enviaram cartas de adesão à sociedade recém-criada. Analisando este primeiro grupo de quarenta e dois membros "fundadores" da Sociedade, percebemos que quarenta deles tornaram-se membros efetivos, residindo e clinicando no Distrito Federal, e dois tornaram-se sócios correspondentes. ${ }^{63}$ Do total de sócios fundadores, sabemos que trinta e um deles, pelo menos, eram formados pela Faculdade de Medicina do Rio de Janeiro e cinco pela Faculdade de Medicina da Bahia; e que vinte e quatro estiveram ou estavam ligados, no ano de fundação da Sociedade, ao Hospício Nacional de Alienados ou às Colônias de Alienados da Ilha do Governador, ou seja, ligados às instituições da Assistência a Alienados. Dos dezoito membros restantes, 
apuramos que dezesseis não mantinham vínculos funcionais com a Assistência, trabalhando em outras instituições de educação e saúde, como a Faculdade de Medicina do Rio de Janeiro, a Santa Casa de Misericórdia, o Serviço Médico Legal, o Serviço de Saúde Pública Municipal e também em clínicas e hospitais particulares, observando que em alguns casos os médicos acumulavam funções em mais de uma destas instituições. Também foram encontrados registros de que pelo menos vinte e dois membros fundadores possuíam consultório próprio no período entre 1907 e 1910, e que, dentre estes, pelo menos Antonio Austregesilo, Carlos Eiras ${ }^{64}$, Carlos M. Sampaio, Henrique Rôxo ${ }^{65}$ (1877-1969) e Waldemar Schiller ${ }^{66}$ (1880-1940) possuíam consultórios particulares onde ofereciam tratamento para moléstias nervosas e mentais. ${ }^{67}$

Entre os fundadores, pelo menos oito eram médicos generalistas, dezesseis eram alienistas, oito trabalhavam no campo da medicina legal e os demais se dividiam entre especialidades diferentes daquelas a que a Sociedade se dedicava. Entretanto, alguns destes últimos médicos ocupavam cargos no HNA, como era o caso de Fernandes Figueira ${ }^{68}$ (1863-1928), pediatra daquela instituição. Porém, é perceptível que o grupo de médicos interessados no estudo da medicina mental precisou contar com o apoio político de médicos generalistas e de outras especialidades para criar a SBNPML, uma vez que alguns destes pertenciam à elite médica carioca, com cargos de grande influência na FMRJ, hospitais e associações médicas. ${ }^{69}$

Dividimos aqui o grupo de sócios fundadores da Sociedade, de acordo com a geração a que pertenciam, em três categorias analíticas: sênior, estabelecidos e iniciantes, como podemos observar na tabela a seguir.

Tabela I: Membros fundadores da SBNPML

\begin{tabular}{|c|c|c|c|}
\hline Membros Fundadores & Especialidade & Cargo ocupado em 1907 & Status prof. \\
\hline Carlos F. Eiras & Generalista & Diretor proprietário da Casa de Saúde Dr. Eiras. & Sênior \\
\hline Antonio A. de Azevedo Sodré (1863-1929) & Generalista & Professor de clínica médica da FMRJ & Sênior \\
\hline Antonio Dias de Barros (1871-1928) & Generalista & Professor da cadeira de bacteriologia da FMRJ & Sênior \\
\hline Alfredo T. de Britto (1863-1909) & Generalista & Diretor da Faculdade de Medicina da Bahia & Sênior \\
\hline Miguel de 0. Couto (1865-1934) & Generalista & Prof. de clínica propedêutica & Sênior \\
\hline Antonio Epimacho C. de Albuquerque & Psiquiatria & $\begin{array}{l}\text { Membro da comissão inspetora dos estabelecimentos } \\
\text { de alienados }\end{array}$ & Sênior \\
\hline João C. Teixeira Brandão (1854-1921) & Psiquiatria & Deputado Federal & Sênior \\
\hline Lúcio Joaquim de Oliveira (?-1908) & Psiquiatria & Alienista do HNA & Sênior \\
\hline Domingos Araújo L. da Silva (?-1908) & Psiquiatria & Dir. das Colônia de Alienados da Ilha do Governador & Sênior \\
\hline Epaminondas de Moraes Martins (1859-1941) & Psiquiatria & Chefe do Departamento de Saúde do Estado do RJ & Sênior \\
\hline José S.de L. Braule Pinto (1865-1918) & Psiquiatria & Alienista das Colônia de Alienados da Ilha do Gov. & Sênior \\
\hline Ernesto Nascimento Silva (1857-1925) & Medicina Legal & Lente de medicina legal da FMRJ & Sênior \\
\hline Agostinho J. de Souza Lima (1842-1921) & Medicina Legal & Prof. de medicina pública da Faculdade de Direito RJ & Sênior \\
\hline Manuel C. do Rego Barros & Medicina Legal & Perito do Serviço Médico Legal & Sênior \\
\hline Antonio Fernandes Figueira (1863-1928) & Pediatra & Chefe do Pavilhão Bourneville do HNA & Sênior \\
\hline Aureliano Vieira W. Machado (1863-1929) & $\begin{array}{l}\text { Dermato- } \\
\text { sifiligrafia }\end{array}$ & Chefe do serviço de dermato-sifiligrafia & Sênior \\
\hline Manoel Bomfim (1868-1932) & Psicologia & Diretor do Pedagogium & Sênior \\
\hline José Chardinal Arpenans (1866-1915) & Oftalmologia & Oftalmologista do HNA & Sênior \\
\hline Marcio Filaphiano Nery & Psiquiatria & Alienista da Assistência do Amazonas & Sênior \\
\hline Miguel Pereira (1871-1918) & Generalista & Chefe do Pav. de moléstias infecciosas do HNA & Estabelecido \\
\hline Juvenil da Rocha Vaz (1881-?) & Generalista & Médico do pavilhão de moléstias infecciosas & Estabelecido \\
\hline Antonio Austregesilo (1876-1961) & Neurologia & Alienista do HNA & Estabelecido \\
\hline
\end{tabular}




\begin{tabular}{|c|c|c|c|}
\hline Henrique Brito de Belford Rôxo (1877-1969) & Psiquiatria & Professor substituto de clínica psiquiátrica do HNA & Estabelecido \\
\hline Humberto Neto Gotuzzo & Psiquiatria & Alienista adjunto do HNA & Estabelecido \\
\hline Juliano Moreira (1873-1933) & Psiquiatria & Diretor do HNA & Estabelecido \\
\hline Waldemar da P. Ribeiro Schiller (1880-1940) & Psiquiatria & Alienista da Casa de Saúde Dr. Eiras & Estabelecido \\
\hline Júlio Afranio Peixoto (1876-1947) & Medicina Legal & Chefe do Serviço Médico Legal & Estabelecido \\
\hline Carlos Pinto Seidl (1867-1929) & Medicina Legal & Diretor do Hospital São Sebastião & Estabelecido \\
\hline Alvaro Andrade Ramos (?-1921) & $\begin{array}{l}\text { Cirurgião e } \\
\text { ginecologista }\end{array}$ & Cirurgião e chefe da seção de cirurgia do HNA & Estabelecido \\
\hline Francisco Pinheiro Guimarães (1871-?) & Patologista & Professor de Patologia geral da FMRJ & Estabelecido \\
\hline Raul Leitão da Cunha (1881-1947) & $\begin{array}{l}\text { Anatomia e } \\
\text { microbiologia }\end{array}$ & $\begin{array}{l}\text { Professor substituto da cadeira de anatomia-patoló- } \\
\text { gica }\end{array}$ & Estabelecido \\
\hline José Antonio de A. Fialho (1874-1940) & Oftalmologia & Professor de oftalmologia da FMRJ & Estabelecido \\
\hline Henrique Dias Duque Estrada & Generalista & Assistente de clínica propedêutica da FMRJ & Iniciante \\
\hline Bruno Alvares da Silva Lobo (1884-?) & $\begin{array}{l}\text { Patologia e } \\
\text { microbiologia }\end{array}$ & Diretor do laboratório de anatomia patológica do HNA & Iniciante \\
\hline Miguel Dantas Salles & Medicina Legal & Médico legista do SML & Iniciante \\
\hline Diogenes de A. Sampaio (1885-1919) & Medicina Legal & Médico legista do SML & Iniciante \\
\hline J. Cesar Suzano Brandão & Medicina Legal & Médico legista do SML & Iniciante \\
\hline Jayme Gonçalves & Psiquiatria & Interno do HNA, exonerado em 1907. & Iniciante \\
\hline Gastão de 0. Guimarães & Psiquiatria & Alienista adjunto do HNA & Iniciante \\
\hline Ulysses Machado P. Vianna Filho (1880-1935) & Psiquiatria & Alienista adjunto do HNA & Iniciante \\
\hline Carlos Mattoso Sampaio Corrêa & Psiquiatria & Alienista adjunto do HNA & Iniciante \\
\hline José de Oliveira Botelho & Saúde Pública & Informação não encontrada & $\mid--------$ \\
\hline
\end{tabular}

A maioria dos fundadores pertencia ao grupo de profissionais que denominamos como sênior, pois consideramos que estes já possuíam uma situação estável na carreira médica há mais de uma década, alguns deles com renome na área. Este grupo sênior parece ter emprestado seu prestígio e influência para que a Sociedade fosse constituída, porém poucos dentre eles frequentaram as reuniões desta entidade, ao longo dos anos seguintes. Os membros deste grupo estavam situados em uma faixa etária acima dos 40 anos, formaram-se em medicina entre 1860 e 1895 e ocupavam cargos médios ou de chefia dentro dos hospitais e hospícios, assim como na FMRJ, já há alguns anos. Alguns destes médicos, como mencionamos anteriormente, já eram consagrados entre a comunidade médica do Distrito Federal, como Souza Lima, na medicina legal; Azevedo Sodré e Miguel Couto, como generalistas; e Teixeira Brandão, como alienista. Neste grupo de fundadores, ao contrário dos outros dois - estabelecidos e iniciantes -, a maioria dos médicos não se dedicava à medicina mental. A participação dos membros deste grupo, na criação da SBNPML, conferia-lhe respeitabilidade e reconhecimento dentro da área médica, por conta das funções que estes desempenhavam na clínica e no ensino da medicina, e também devido à sua participação em outras sociedades médicas do período, como a Academia Nacional de Medicina. Alguns dos membros sênior ${ }^{70}$ tornaram-se membros honorários da Sociedade ainda nas primeiras duas décadas de existência desta instituição. ${ }^{71}$

Além do grupo de médicos sênior, também participaram da fundação da Sociedade médicos com carreiras já estabelecidas que estavam se especializando na área da medicina mental, alguns destes em processo de ascensão profissional (Ver tabela I). Este segundo grupo era formado por aqueles que concluíram o curso de medicina entre os anos de 1890 e 1903 e estavam situados em uma faixa etária entre 30 e 40 anos. Alguns destes médicos, como Juvenil da Rocha Vaz (1881-?), Austregesilo, Alvaro Ramos ${ }^{72}$ e Humberto Gotuzzo, trabalhavam como alienistas no HNA, enquanto outros, como Raul Leitão da Cunha (1881-1947) e Miguel Pereira (1871-1918), recém-nomeados professores substitutos da FMRJ, haviam acabado de ser exonerados das funções que exerciam no HNA, o primeiro como chefe do laboratório 
anatomopatológico e o segundo como médico chefe da seção de moléstias intercorrentes. Alguns dos "estabelecidos" haviam assumido cargos de destaque, a exemplo de Juliano Moreira, diretor do HNA, José Antonio de Abreu Fialho (1874-1940), professor de oftalmologia da FMRJ, e Afranio Peixoto, recém-nomeado diretor do Serviço Médico Legal.

Entre os fundadores, existia também o grupo de médicos que denominamos de "iniciantes", constituído por aqueles que eram recém-formados em 1907, situados em uma faixa etária entre 20 e 30 anos e que estavam em seu primeiro emprego (Ver tabela I). Alguns eram assistentes na FMRJ, como Henrique Duque, ou desempenhavam a função de alienistas adjuntos do HNA, como Carlos Sampaio Corrêa, Ulysses Vianna (1880-1935) ${ }^{73}$ e Gastão Guimarães, todos recém-formados. Outros, como Jayme Gonçalves, eram médicos internos no hospício recém-exonerados, pois tinham acabado de concluir o curso de medicina. E existiam casos, como os de Diogenes Sampaio (1885-1919) e Miguel Salles, de peritos do Serviço Médico Legal recém-admitidos no cargo, por concurso.

Nos anos seguintes à criação da Sociedade, formou-se um pequeno grupo de sócios fundadores que efetivamente participavam das reuniões da instituição e decidiam seu destino enquanto membros da sua diretoria. Estes pertenciam principalmente ao grupo dos "estabelecidos", com apoio de alguns dos fundadores "iniciantes" e também de sócios admitidos ao longo das décadas seguintes. Assim, durante seus primeiros vinte e seis anos de funcionamento, a direção da Sociedade manteve-se centralizada na pessoa de Juliano Moreira, eleito seu presidente perpétuo desde 1914. Este administrou a instituição com o auxílio de um grupo seleto de colaboradores, formado por Henrique Roxo, Antonio Austregesilo, Ulysses Vianna, todos membros fundadores da Sociedade, e Waldemar de Almeida, ${ }^{74}$ admitido no primeiro ano de funcionamento da agremiação. Apesar da entidade contar com um amplo quadro de sócios efetivos ao longo das primeiras décadas de sua existência, este período foi marcado pela centralização administrativa e pela lenta renovação na diretoria da entidade, controlada durante muito tempo apenas por alguns dos membros fundadores.

\section{A psiquiatria, a neurologia e a medicina legal dentro da SBNPML}

Logo após a fundação da SBNPML, seus membros definiram como um dos objetivos principais da agremiação trabalhar em prol do desenvolvimento dos "ramos do conhecimento" médico que a nomeavam - psiquiatria, neurologia e medicina legal. De maneira que, no ano seguinte à sua criação, foram estabelecidas três comissões, cada uma composta por três sócios, representando aquelas especialidades da medicina. Entretanto, pelo menos até 1915, não havia nas reuniões da Sociedade uma demarcação clara dos temas a serem discutidos por área, de maneira que todos os casos clínicos e comunicações apresentadas eram analisados e debatidos tanto por aqueles membros que se interessavam pelo estudo das doenças mentais como pelos que se preocupavam em tratar das moléstias do sistema nervoso e também por alguns que se dedicavam à perícia médica. Após a reforma do primeiro estatuto da SBNPML, em 1915, iniciou-se um movimento entre os sócios da agremiação, que se estendeu até o final da década de 1920, em busca de uma maior independência das áreas, com a criação de sessões separadas, presididas por um representante de cada especialidade.

Porém, de maneira semelhante à constituição de outras especialidades do conhecimento médico, o processo de demarcação de limites de atuação entre as áreas da medicina mental - mais especificamente, da psiquiatria e neurologia entre si e em relação à medicina legal - não foi rápido, uniforme ou linear. A SBNPML acompanhou este processo mais amplo, de modo que observamos oscilações na forma como os membros da agremiação definiam a área em que atuavam, assim como o objeto de estudo de cada especialidade.

A forma como era empregado o termo alienista, durante o primeiro período de existência da Sociedade (19071915), é um exemplo da dubiedade de movimentos dos seus membros em relação às áreas em que buscavam se especializar. De um lado, nas atas de reunião daquela instituição - assim como no periódico que a representava, os Arquivos Brasileiros -, o termo "alienista" era utilizado de forma ampla e indiscriminada, abrangendo também os estudiosos do sistema nervoso; pois, neste período, estes médicos procuravam tratar tanto das "doenças mentais" 
como daquelas que atingiam o sistema nervoso. Por outro lado, os sócios da SBNPML procuravam estabelecer uma diferenciação entre os alienistas, enquanto médicos que tratavam das doenças mentais estudadas pela psiquiatria; os neurologistas, enquanto médicos que estudavam e tratavam das moléstias relacionadas ao sistema nervoso, e os médicos legistas, como encarregados das perícias médicas. Um exemplo dessa diferenciação pode ser percebido nos debates sobre a realização do primeiro Congresso Brasileiro de Alienistas, Neurologistas e Médicos Legistas, em 1910, que, de maneira semelhante aos congressos internacionais, dividia-se por "ramos do conhecimento da medicina". ${ }^{75}$

Esta dubiedade, que marcou o processo de formação destas categorias de profissionais dedicados à medicina mental até as primeiras décadas do século XX, também pode ser observada no fato do termo "psiquiatra" não ser utilizado para nomear os médicos brasileiros dedicados a esta área da medicina, apesar do termo "psiquiatria" ser empregado no nome da Sociedade e nos textos e atas da entidade publicados no periódico Arquivos Brasileiros para designar o ramo da medicina preocupado com o estudo e o tratamento das doenças mentais. Na SBNPML, foi apenas a partir de 1913 que os termos "psiquiatra" e "neuriatra" começaram a ser empregados para especificar a especialidade a que se dedicava prioritariamente cada médico.

Mesmo assim, na Sociedade era relativamente comum seus membros se definirem como atuando nas áreas da psiquiatria e da neurologia simultaneamente. 0 papel desempenhado por Juliano Moreira enquanto representante brasileiro no Congresso de Londres como alienista e no de Gand como neurólogo é um exemplo desta dupla atuação. Do mesmo modo, observa-se esta dubiedade nas funções desempenhadas por Henrique Roxo na FMRJ, como professor substituto de clínica psiquiátrica e moléstias nervosas da mesma faculdade entre 1904-1911.

Ao mesmo tempo, na SBNPML também foram apresentados e debatidos estudos, por seus membros, sobre outros conhecimentos relativos à medicina mental - a psicologia experimental e a psicanálise -, ainda que em menor escala, uma vez que estas matérias eram tratadas dentro da Sociedade como especialidades acessórias no tratamento das "doenças mentais e moléstias nervosas".

Sobre a influência da psicologia experimental na Sociedade na sua primeira década de funcionamento, podemos observar 0 interesse de alguns de seus membros em desenvolver estudos sobre 0 assunto em suas teses de doutoramento, como foi o caso de Henrique Roxo, que, em 1900, defendeu a tese intitulada "Duração dos atos psíquicos elementares nos alienados", Maurício de Medeiros ${ }^{76}$ (1885-1966), que publicou nos Arquivos Brasileiros um texto intitulado "A questão dos métodos em psicologia", baseado em sua tese, defendida em 1907, e Plínio Olinto77 (18861956), cuja tese defendida em 1910 tratava sobre a "Contribuição ao estudo da associação de ideias". Este último, ao tomar posse como novo sócio, logo após ter se formado, apresentou à Sociedade uma comunicação baseada em sua tese, sobre o diagnóstico diferencial entre casos de demência precoce e loucura maníaca depressiva através da utilização do método da associação de ideias.

Observamos a presença da psicologia também no convite feito pela Sociedade ao psicólogo francês George Dumas $^{78}$ quando da sua vinda ao Rio de Janeiro, em 1908, para que ministrasse uma série de conferências sobre temas do campo. Este professor da Sorbonne veio ao Brasil, também, como encarregado do governo francês, com o objetivo de firmar um acordo de cooperação entre as universidades da França e as faculdades brasileiras. Ele ainda voltou a ministrar palestras na SBNPML em outras oportunidades, em 1917 e 1925.

A primeira visita de Dumas ao Brasil, em 1908, foi de grande importância para a SBNPML no seu primeiro ano de funcionamento, pois representava o início da participação da entidade como organizadora de palestras e conferências de vulgarização da ciência e também possibilitava o estreitamento de suas relações oficiais com outras instituições internacionais da mesma área, como, por exemplo, a Sociedade de Psicologia Francesa, da qual Dumas fazia parte. Neste contexto, a Sociedade, ainda em processo de estruturação, contava com o prestígio de alguns de seus sócios, como Juliano Moreira, que mantinha relações oficiais, enquanto diretor do Hospício Nacional de Alienados, com instituições acadêmicas e de assistência de outros países e também contatos pessoais, provenientes de suas viagens à Europa e sua participação em sociedades estrangeiras, para intermediar os contatos externos, principalmente com as comunidades médicas francesa e alemã. 
Alguns dias após seu desembarque no Rio de Janeiro, o psicólogo francês, aceitando o convite da SBNPML, participou de uma sessão da entidade que foi inicialmente presidida por Manoel Bomfim, ${ }^{79}$ criador do laboratório de psicologia experimental do Pedagogium. Nesta reunião, Dumas defendeu a ideia de uma aproximação entre "cientistas franceses e brasileiros, para que houvesse principalmente permuta de trabalhos" entre a SBNPML e a Sociedade de Psicologia Francesa. ${ }^{80}$

A primeira referência à psicanálise encontrada nas atas de reuniões da Sociedade data de 1914, por ocasião da apresentação de Pedro Pernambuco sobre "um caso de epilepsia onde fenômenos de automutilação substituíam os ataques". Naquela ocasião, Austregesilo fez considerações sobre o caso, classificando os automutiladores em "inconscientes, subconscientes e conscientes", propondo também que a próxima sessão fosse dedicada à psicanálise, por considerá-la como um "assunto de suma importância" que precisava ser melhor estudado por eles. ${ }^{81}$ Porém, foi só a partir da década de 1920 que a influência da psicanálise nos debates da SBNPML intensificou-se.

\section{Considerações finais}

A fundação da Sociedade, como pudemos observar, aconteceu em um contexto de entusiasmo, juntamente com a preparação para a realização da Exposição de 1908 e do IV Congresso Médico Latino-Americano de 1909. Estes, por sua vez, eram expressão dos anseios de uma elite intelectual do início do século XX, que apresentava projetos e propostas para a construção de uma identidade nacional, tendo como pilares a "modernização" urbana e a "civilização" da população, embasados em saberes provenientes da medicina, educação e engenharia. ${ }^{82}$

Neste contexto, era comum que os médicos participassem de uma série de sociedades e associações de caráter médico, científico e também literário. Estas agregavam os interesses comuns de uma elite intelectual e de subgrupos profissionais, no caso das sociedades especializadas. Percebemos que, para os membros da SBNPML, estar inserido nesta, como em outras agremiações, significava participar de um movimento de especialização das áreas da medicina, buscar a legitimação e institucionalização daquela atividade e, ao mesmo tempo, se reconhecer como profissional daquelas áreas. Isto ocorria dentro de um contexto mais amplo que envolvia a constituição e autodeterminação de identidades especializadas no campo médico científico e de uma identidade nacional.

Observamos que a história do ato de criação da Sociedade, enquanto fato histórico revestido de simbolismos para a comunidade que representava e narrado como mito de origem, serviu de alicerce para a construção da identidade tanto da associação, de caráter médico-científico, como do seu grupo de associados. Ao mesmo tempo, a criação desta instituição reforçava as iniciativas e trabalhos em prol da institucionalização da psiquiatria e neurologia e modernização da medicina legal, já desenvolvidos por um grupo de médicos que se reuniam em torno do periódico Arquivos Brasileiros desde a sua criação, em 1905. Apesar disto, a fundação institucional da Sociedade, em 1907, representava uma resposta ao anseio pela ampliação e sistematização dos espaços de debate e de legitimação das três áreas do conhecimento médico a que se refere, frente à comunidade médica já estabelecida e a determinados setores da sociedade leiga, como o Estado, uma vez que a SBNPML, enquanto instituição, teria maior força agregadora e mais meios de buscar a concretização das ideias e posicionamentos defendidos no periódico, pelo menos em tese.

Em relação às suas áreas internas, percebemos que a Sociedade acabou por favorecer muito mais o desenvolvimento institucional da psiquiatria e da neurologia que da medicina legal, até porque esta última já estava mais estruturada do que as duas primeiras, enquanto área específica da medicina, no momento da criação da SBNPML. Porém, a Sociedade também representou um espaço de debate, mesmo que em menor escala, para as questões referentes à modernização e profissionalização da medicina legal..$^{83}$

0 surgimento da SBNPML, portanto, estava inserido em um movimento mais amplo no sentido de uma maior valorização das especialidades, o que ocorreu com a medicina em geral na época. No entanto, ela recorreu a representantes 
de um paradigma médico generalista anterior, como apoio no momento de sua fundação. Embora esse grupo de médicos generalistas tenha emprestado seu prestígio e influência, legitimando 0 ato de fundação, no funcionamento posterior da Sociedade não se percebe um envolvimento deste primeiro grupo com a entidade, mas sim uma centralização da administração desta em torno de um grupo mais modesto numericamente e com um perfil mais especializado. Portanto, sua constituição ocorreu em um contexto de mudança no perfil dos médicos e das instituições que os representavam, mudança que se acentuou durante as décadas seguintes de funcionamento da Sociedade.

\section{Notas e referências bibliográficas}

Ede C. B. Cerqueira é historiadora pela Universidade do Estado da Bahia; mestre e doutoranda pelo Programa de Pós-Graduação em História das Ciências e da Saúde da Casa de Oswaldo Cruz/Fiocruz.

1 FERREIRA, L. 0.; MAIO, M. C.; AZEVEDO, N. A Sociedade de Medicina e Cirurgia do Rio de Janeiro: a gênese de uma rede institucional alternativa. História, Ciências, Saúde - Manguinhos, Rio de Janeiro, IV(3): nov. 1997-fev. 1998, p. 477.

2 FIGUEIRÔA, S. F. M. Instituições científicas e formas de institucionalização do saber. Terra Brasilis [Online], n.2, 2000. Disponível em http://terrabrasilis. revues.org. Consultada em 27/02/2015.

3 DANTES, Maria Amélia M. Introdução. In: DANTES, Maria Amélia M. (Org.). Espaços de ciência no Brasil: 1800-1930. Rio de Janeiro: Editora Fiocruz, 2001, p.19.

4 FIGUEIRÔA, op. cit., 2000.

5 Este artigo apresenta parte do conteúdo discutido no capítulo I da minha dissertação de mestrado. Ver CERQUEIRA, E. A Sociedade Brasileira de Neurologia, Psiquiatria e Medicina Legal: Debates sobre ciência e assistência psiquiátrica (1907-1933). Dissertação de Mestrado em História das Ciências e da Saúde. Rio de Janeiro: COC - Fiocruz, 2014.

6 Ver: VENANCIO, A. T. Sociedade Brasileira de Neurologia, Psiquiatria e Medicina Legal (1907-1957?). In: JACÓ-VILELA, A. (Org.). Dicionário Histórico de Instituições de Psicologia no Brasil. Rio de Janeiro: Imago; Brasília: CFP, 2011.

7 Ver: AMARANTE, P. (Coord.). Projeto Memória da Psiquiatria no Brasil. Catálogo de Periódicos não-correntes em Psiquiatria da Biblioteca de Manguinhos. CD. Rio de Janeiro: Fundação Oswaldo Cruz, 2004; FACCHINETTI, C.; CUPELLO, P.; EVANGELISTA, D. F. Arquivos Brasileiros de Neurologia, Psiquiatria e Ciências Afins: uma fonte com muita história. História, Ciências, Saúde - Manguinhos, Rio de Janeiro, v. 17, supl. 2, dez. 2010.

8 Sobre a história da SBNPML no período de 1907 a 1933, ver: CERQUEIRA, op. cit., 2014.

9 Ver: MANNHEIM, K. 0 problema da intelligentsia. Um estudo de seu papel no passado e no presente. In: MANNHEIM, K. Sociologia da Cultura. São Paulo: Perspectiva, 2004, pp. 69-139; SIRINELLI, J. Os intelectuais. In: RÉMOND, R. (Org.). Por uma história política. 2ª ed. Rio de Janeiro: Editora FGV, 2003.

10 SIRINELLI, op. cit., 2003, p. 254-255.

11 Fase das obras de remodelação da capital da República, assim conhecido popularmente por concentrar o maior número de demolições de cortiços e prédios coloniais do centro do Rio de Janeiro, este movimento repetiu-se em outras capitais do país como São Paulo e Salvador, ainda nas primeiras décadas do século XX. Também foi tema da literatura de costumes. Ver: VIEIRA, J. 0 Bota-Abaixo. Crônica de 1904. Rio de Janeiro: Ed. Selma, s.d.

12 Ver: BENCHIMOL, J. L. Pereira Passos: um Haussmann tropical - a renovação urbana da cidade do Rio de Janeiro no início do século XX. Rio de Janeiro: Secretaria Municipal de Cultura, Turismo e Esportes/Departamento Geral de Documentação e Informação Cultural/ Divisão de Editoração, 1992 , p. 139.

13 Idem, p. 229

14 Um exemplo do descontentamento popular com as medidas de remodelação da urbe e controle de epidemias foi a Revolta da Vacina. Ver: BENCHIMOL, op. cit. , 1992; e CHALHOUB, S. Cidade Febril. Cortiços e epidemias na corte imperial. São Paulo: Companhia das Letras, 2006 [1996].

150 Brasil até então havia participado de todas as edições das Exposições Universais: 1851 e 1862 em Londres; 1855, 1867 e 1889 em Paris; 1893 em Chicago; e 1904 em Saint Louis. Nas duas exposições realizadas nos EUA, o Brasil recebeu medalhas por projetos de engenharia, sendo premiado em Saint Louis pelo projeto do Palácio Monroe, que lhe serviu de pavilhão na exposição, e que mais tarde foi remontado na recém inaugurada Avenida Central do Rio de Janeiro, como sede do Senado. Ver: PEREIRA, M. S. A Exposição de 1908 ou o Brasil visto por dentro. Arqtexto, Revista do Programa de Pós-Graduação em Arquitetura da UFRGS, vol. 16, s.d., pp. 11-13. Disponível em http://www.ufrgs.br. Acesso em 26/02/2015.

$16 \quad$ Idem, p. 11-15.

17 Idem.

18 Ver LIMA, N. T. Um sertão chamado Brasil: intelectuais e representações da identidade nacional. Rio de Janeiro: luperj; Revan, 1999

19 LIMA, N. T.; HOCHMAN, G. Condenado pela raça, absolvido pela medicina: o Brasil descoberto pelo Movimento Sanitarista da Primeira República. In: MAIO, M. C. (Org.). Raça, ciência e sociedade. Rio de Janeiro: FIOCRUZ/CCBB, 1996, pp. 26-27.

20 Manoel Bomfim, médico, diretor do Pedagogium entre 1897-1919 e criador do Laboratório de Psicologia Pedagógica. Ver: LOURENÇO FILHO, M. B. A Psicologia no Brasil. In: AZEVEDO, F. (Org.). As Ciências no Brasil, vol. 2. $2^{\text {a }}$ ed. Rio de Janeiro: Editora UFRJ, 1994, p.313.

21 BOMFIM, M. A América Latina: Males de Origem. Rio de Janeiro: Topbooks, 2005, pp. 327-339.

22 Ver: LIMA; HOCHMAN, op. cit., 1996, p. 26-31. 
EDLER, F. C. "O debate em torno da medicina experimental no Segundo Reinado". História, Ciências, Saúde - Manguinhos, Rio de Janeiro, v. 3 (2), jul.-out. 1996, p. 285.

24 SÁ, D. M. de. A ciência como profissão: médicos, bacharéis e cientistas no Brasil (1895-1935). Rio de Janeiro: Editora Fiocruz, 2006, p. 82.

25 Sobre esse perfil médico anterior, mais generalista, ver: FERREIRA, L. O.; FONSECA, M. R. F.; EDLER, F. C. A Faculdade de Medicina do Rio de Janeiro no século XIX: a organização institucional e modelos de ensino. In: DANTES, M. A. M. (Org.). Espaços de ciência no Brasil: 1800-1930. Rio de Janeiro: Editora Fiocruz, 2001 e PEREIRA NETO, A. F. Ser médico no Brasil: o presente no passado. Rio de Janeiro: Editora Fiocruz, 2009.

26 CERQUEIRA, op. cit., 2014, p. 39

270 médico Júlio Afranio Peixoto é um exemplo deste perfil multifacetado, do especialista em medicina legal que simultaneamente foi "educador, artista, escritor, crítico, cronista, poeta, ensaísta, historiador, professor", político e administrador público. Ver: HERSCHMANN, M.; KROPF, S.; NUNES, C. Missionários do progresso: médicos, engenheiros e educadores no Rio de Janeiro, 1870-1937. Rio de Janeiro: Diadorim Editora, 1996, p. 38; SILVA, R. P. As ciências de Afrânio Peixoto: higiene, psiquiatria e medicina legal (1892-1935). Tese de Doutorado em História das Ciências e da Saúde, Rio de Janeiro, COC/Fiocruz, 2014.

28 FERREIRA; FONSECA; EDLER, op. cit., 2001, p. 60

29 João Carlos Teixeira Brandão nasceu em São João Marcos, antigo município do Estado do Rio de Janeiro. Doutorou-se pela Faculdade de Medicina do Rio de Janeiro em 1877, defendendo a tese "Operações reclamadas pelo estreito da uretra". Em seguida começou a clinicar na cidade de Barra Mansa, província do Rio de Janeiro, onde exerceu a profissão de 1878 a 1880. Posteriormente, viajou para a Europa, mais especificamente para a França, Alemanha e Itália, para especializar-se em psiquiatria. Em 1883 foi nomeado lente da cadeira de clínica psiquiátrica e de moléstias nervosas da Faculdade Nacional de Medicina e no ano seguinte médico clínico do Hospício Pedro II. Com a criação da Assistência Médico-Legal dos Alienados em 1890, foi nomeado diretor geral desta. Foi também deputado federal pelo Estado do Rio de Janeiro, entre o período de 1903 e 1921, quando falece. (ARAUJO JUNIOR, M. V.; MOREIRA, A.; ROCHA, B. Biografia de João Carlos Teixeira Brandão: de alienista a diretor da $1^{\text {a }}$ Escola de Enfermagem do Brasil. SMAD, Rev. Eletrônica Saúde Mental Álcool Drogas, [on line], 2009, vol.5, n.1, pp. 1-13).

30 BRANDÃO, T. O que é a psiquiatria. Arquivos Brasileiros de Psiquiatria, Neurologia e Ciências Afins, Rio de Janeiro, ano III, n. 2, [1884] 1907, pp. 157-158.

31 FERLA, L. Feios, sujos e malvados sob medida: a utopia médica do biodeterminismo. São Paulo: Alameda, 2009, p. 80

32 NEVES, A. C. O emergir do corpo neurológico: neurologia, psiquiatria e psicologia em São Paulo a partir dos periódicos médicos paulistas (1889-1936). São Paulo: Companhia llimitada, 2010, pp. 65-66.

33 BRASIL. Decreto n. 8.024, de 12 de março de 1881. Manda executar o Regulamento para os exames das Faculdades de Medicina. Art. 35.12 mar. 1881.

34 GOMES, M. M.; TEIVE, H. A. G. História da Neurologia Brasileira. São Paulo: Ominifarma, 2012, p. 12.

35 Antonio Austregesilo Rodrigues de Lima, natural de Recife-PE, doutor em 1899 pela FMRJ, foi alienista do HNA e médico-chefe da $20^{a}$ enfermaria da Santa Casa de Misericórdia do Rio de Janeiro, assistente de clínica propedêutica da FMRJ em 1909, professor substituto em 1911, professor da cadeira de doenças nervosas em 1912 e mais tarde professor catedrático de Neurologia da mesma faculdade. (MAGALHÃES, F. 0 centenário da Faculdade de Medicina do Rio de Janeiro, 1832-1932. Rio de Janeiro: Tipographia A. P. Barthel, 1932, p. 336).

NEVES, op. cit., 2010, p. 65-66.

37 FERREIRA; MAIO; AZEVEDO, op. cit., 1998, p. 476

38 Idem.

39 Idem, pp. 476-477.

40 SÁ, op. cit., 2006, p. 15-16.

41 A Sociedade Brasileira de Pediatria foi fundada em 1910. Ela teve como um dos seus principais idealizadores o médico pediatra Antonio Fernandes Figueira, que era chefe do pavilhão para crianças do HNA.

42 CEROUEIRA, op. cit., 2014, p. 24.

43 Esta sociedade foi criada em 1912, em um dos pavilhões da Santa Casa de Misericórdia do Rio de Janeiro. 0 médico dermatologista e sifilígrafo Fernando Terra, que não era membro da SBNPML, foi seu presidente de 1912 a 1925. (Disponível em www.sbd.org.br. Consultado em 19/03/2015).

440 periódico Arquivos Brasileiros de Psiquiatria, Neurologia e Ciências Afins (1907) foi depois denominado Arquivos Brasileiros de Psiquiatria, Neurologia e Medicina Legal (1908-1918) e mais tarde Arquivos Brasileiros de Neuriatria e Psiquiatria (1919-1957).

45 Juliano Moreira era natural de Salvador-BA. Doutor em medicina em 1891 pela Faculdade de Medicina da Bahia, defendendo a tese: “Sífilis maligna precoce". Foi professor concursado da citada faculdade a partir de 1896 e alienista do Hospício São João de Deus entre 1898-1902. Assumiu o cargo de diretor do Hospício Nacional de Alienados em 1903 e a função de diretor geral da Assistência a Alienados do Distrito Federal em 1911, permanecendo nestas funções até 1930. (PAIM, I. Psiquiatras Brasileiros I. Campo Grande, MS: Editora Oeste, 2003, p. 31).

46 Júlio Afranio Peixoto, natural de Lençóis - BA, diplomou-se pela Faculdade de Medicina da Bahia em 1897, com a tese de doutoramento "Epilepsia e crime". Foi professor substituto de medicina legal da Faculdade de Direito do mesmo estado. Assumiu em 1901 o cargo de médico no HNA e a direção interina deste, durante ausência de Juliano Moreira em 1904. No ano seguinte frequentou os cursos de Strassmann, Haberda, Richter, Landsteiner, Roux, Laveran e Metchnikoff em Berlim, Viena e Paris. Foi aprovado no concurso para professor de medicina pública da FMRJ em 1906, e também foi diretor do Serviço Médico-Legal entre 1907-1913. (Arquivos da Academia Nacional de Medicina, MT234).

47 BRASIL. Decreto n. 5.125, de 01 de fevereiro de 1904. Dá novo regulamento à Assistência a Alienados. Art. 38, parágrafo IV. 01 fev. 1904.

48 CERQUEIRA, op. cit., 2014, p. 28-29.

49 Idem, p. 29-31

50 SBNPML, Boletim. In: Arquivos Brasileiros de Psiquiatria, Neurologia e Ciências Afins, ano III, n. 4, 1907, pp. 435-437.

51 Antonio Augusto de Azevedo Sodré, que era natural do Rio de Janeiro, tornou-se doutor pela Faculdade de Medicina do Rio de Janeiro (FMRJ) em 1885. Foi professor de Clínica Médica da FMRJ (1906) e depois Catedrático de Patologia Interna e diretor da mesma faculdade em 1911-12, membro titular da Academia Nacional de Medicina desde 1898 e presidente desta entre 1905-07 (Disponível em www.anm.org.br. Consultado em 19/02/2015). 

Também foi professor de Medicina Pública na Faculdade de Direito do Rio de Janeiro, no período de 1902 a 1916.

53 Miguel de Oliveira Couto, natural do Rio de Janeiro, doutorou-se em medicina pela Faculdade de Medicina do Rio de Janeiro em 1885. Foi professor catedrático de clínica médica da mesma faculdade, chefe da $18^{\mathrm{a}}$ Enfermaria do Hospital Geral da Santa Casa da Misericórdia do Rio de Janeiro, membro da Academia Nacional de Medicina desde 1897 e presidente perpétuo desta entre 1929 e 1934. Também foi membro efetivo da Sociedade de Medicina e Cirurgia, Sociedade Médica dos Hospitais, Sociedade de Medicina de São Paulo e Academia de Letras do Estado do Rio de Janeiro. (Disponível em www. anm.org.br. Consultado em 19/02/2015).

54 SBNPML, Boletim. In: Arquivos Brasileiros de Neuriatria e Psiquiatria, Rio de Janeiro, ano IX, $2^{0}-3^{\circ}$ trimestre, 1927, p. 130

55 SBNPML, Boletim. In: Arquivos Brasileiros de Neuriatria e Psiquiatria, Rio de Janeiro, ano XXXVII, n.1, 1955, p. 4.

56 Ver os discursos proferidos nas sessões comemorativas de aniversário da SBNPML em: 18/11/1916: 95; 17/11/1917: 218; 17/11/1920: 327-330; 17/11/1922: 52; 17/11/1924: 232-235; 17/11/1925: 228; 17/11/1926: 61-63; 17/11/1928: 164-165; 16/11/1931: 144-145; 17/11/1932: 60-62.

57 Correio Paulistano, 18/11/1907, notícia intitulada "Congresso Médico", na seção de telegramas. Este foi o único dos periódicos consultados que mencionava a fundação da SBNPML. Os demais periódicos pesquisados circulavam no Distrito Federal, a saber: Brazil Médico (1905-1910); Annaes da Academia de Medicina do Rio de Janeiro (1904-1907); Correio da Manhã (1905-1910); Jornal do Commércio (1905-1908); 0 Paiz (1905-1910).

58 Esta comissão era constituída por Azevedo Sodré, como presidente, Jacyntho de Barros, José de Oliveira Botelho e Alvaro Ramos como secretários.

59 O IV Congresso Médico Latino-Americano e a Exposição Internacional de Higiene, anexa a ele, fizeram parte de uma série de congressos médicos iniciados em 1901, na cidade de Santiago do Chile, e que passaram a acontecer a cada dois ou três anos, em um país diferente. 0 segundo congresso aconteceu em Buenos Aires, em 1904, a seguir vieram os de Montevidéu (1907), Rio de Janeiro (1909), Lima (1913) e Havana (1922). Todos estes congressos seguiam os objetivos de estimular o desenvolvimento das ciências médicas, favorecer a utilização de medidas uniformes de proteção sanitária internacional e incentivar o "intercâmbio intelectual" entre instituições, associações e personalidades médicas latino-americanas. Ver: ALMEIDA, M.: Circuito aberto: ideias e intercâmbios médico-científicos na América Latina nos primórdios do século XX. História, Ciências, Saúde - Manguinhos, Rio de Janeiro, v.13, n. 3, jul.-set. 2006, p. 742.

60 Comparando a lista de membros fundadores da Sociedade com a comissão executiva e seções organizadas para o IV CMLA, encontramos os seguintes nomes em comum: Azevedo Sodré, Afranio Peixoto, Humberto Gotuzzo, J. Oliveira Botelho, Alvaro Ramos, Jacyntho de Barros, Teixeira Brandão, Dias de Barros, Leitão da Cunha, Miguel Couto, Juliano Moreira, Fernandes Figueira, Antonio Austregesilo, H. Duque Estrada, Nascimento Silva, Carlos Seidl, Abreu Fialho e Werneck Machado. (Brazil Médico, 1907, p. 378).

61 Azevedo Sodré, Miguel Couto, Nascimento Silva, Juliano Moreira, Fernandes Figueira, Carlos Eiras, Dias de Barros, Afranio Peixoto, Miguel Pereira, Abreu Fialho, Alvaro Ramos, Carlos Seidl, Leitão da Cunha, Waldemar Schiller, Werneck Machado, Lúcio de Oliveira, Chardinal, Braule Pinto, Bruno A. da Silva Lobo, Rocha Vaz, José de Oliveira Botelho, Ulysses Vianna Filho, Diogenes Sampaio, Miguel Dantas Salles, Henrique Duque Estrada, Manoel Bomfim, Carlos Sampaio, Epimacho, Jayme Gonçalves, Gastão Guimarães e Henrique Rôxo, que não é citado no texto mas foi um dos designados para elaborar os estatutos da Sociedade. (SBNPML, op. cit., 1907, p.436).

62 Agostinho José de Souza Lima, João Carlos Teixeira Brandão, Alfredo de Britto, Marcio Nery, Austregesilo, Humberto Gotuzzo, Pinheiro Guimarães, Manoel do Rego Barros, Domingos de Araujo, Suzano Brandão e Epaminondas Martins. (Idem).

63 Os dois fundadores que se tornaram membros correspondentes são: Alfredo Thomé de Brito (1863-1909), diretor da Faculdade de Medicina do Estado da Bahia entre 1901-1908, e Jayme Gonçalves, recém-formado na Faculdade de Medicina do Rio de Janeiro e ex-interno do Hospício Nacional de Alienados, que em 1908 mudou-se para o estado de São Paulo.

64 Carlos Fernandes Eiras, diretor da Casa de Saúde Dr. Eiras desde a morte do pai, Manoel Joaquim Fernandes Eiras (1828-1889), antigo proprietário e administrador da citada casa de saúde, que, desde a segunda metade do século XIX, recebia convalescentes e alienados. Carlos Eiras formou-se pela FMRJ em 1877, defendendo a tese "Indicações e Contra Indicações da Hidroterapia no Tratamento das Moléstias do Sistema Nervoso" e foi um dos fundadores da Policlínica Botafogo, em 1900. (PICCININI, W. J. Casa de Saúde Dr. Eiras: crônica de seu desaparecimento. Psychiatry on line Brazil, v. 13, n. 3, mar. 2008, disponível em http://www.polbr.med.br/ano08/wal0308.php, consultado em 01/05/2015).

65 Henrique Britto de Belford Rôxo, doutor pela FMRJ em 1900, defendeu a tese "Duração dos atos psíquicos elementares nos alienados". Foi assistente de clínica psiquiátrica da Faculdade de Medicina do Rio de Janeiro e depois professor substituto da mesma nos períodos de 1904-1907 e 1911-1920. Em 1921 , Rôxo assumiu a citada cátedra como professor titular até sua aposentadoria em 1945. Durante este período, ele também foi diretor da Clínica Psiquiátrica da FMRJ. Ver: VENANCIO, A. T. Os alienados segundo Henrique Rôxo: Ciência psiquiátrica no Brasil no início do século XX. Culturas Psi, v. 0, 2012 , p. 32.

66 Waldemar Schiller, médico alienista da Casa de Saúde Dr. Eiras (1908), exerceu também a atividade de diretor desta casa a partir de 1909 (FACCHINETTl; CUPELLO; EVANGELISTA, op. cit., 2010, p. 533, nota 13).

67 CERQUEIRA, op. cit., 2014, pp. 48-49.

68 Antonio Fernandes Figueira, natural do Rio de Janeiro, doutor em medicina pela Faculdade de Medicina do Rio de Janeiro em 1886, foi pediatra, chefe do Pavilhão Bourneville, destinado ao tratamento de crianças no HNA, desde 1903. Também foi pediatra da Santa Casa de Misericórdia e fundador da Policlínica das Crianças, criada em 1909. Membro da ANM desde 1903, foi fundador e presidente perpétuo da Sociedade Brasileira de Pediatria de 19101927. (Disponível em www.anm.org.br. Consultado em 20/02/2015).

69 São exemplos desta situação de médicos que já possuíam em 1907 um elevado status profissional na comunidade médica carioca: Azevedo Sodré, Miguel Couto, Fernandes Figueira.

70 Azevedo Sodré, Ernesto Nascimento Silva, Antonio Dias de Barros, Domingos Niobey, Agostinho J. de Souza Lima, Teixeira Brandão. (SBNPML, Lista dos membros da SBNPML. In: Arquivos Brasileiros de Psiquiatria, Neurologia e Medicina Legal, Rio de Janeiro, ano II, $1^{0}$ trimestre1920, p. 73-76).

71 CERQUEIRA, op. cit., 2014, p. 49-50.

72 Alvaro Andrade Ramos foi médico cirurgião ginecologista do Hospício Nacional de Alienados (HNA) de 1903 até 1921, quando faleceu, sendo substituído pelo irmão e discípulo Oscar Porphirio de Andrade Ramos. (Brasil, Ministério da Justiça e Negócios Interiores. Relatório apresentado ao Presidente da República dos Estados Unidos do Brasil. Rio de Janeiro: Imprensa Nacional, 1904, p. 323; 1922, p. 70. Disponível em http://brazil.crl.edu. Consultado em 20/02/2015). 
73 Ulysses Machado Pereira Vianna Filho nasceu no Recife, onde estudou até 1899, quando mudou-se para o Rio de Janeiro a fim de cursar medicina na FMRJ; entretanto, dois anos depois, transferiu-se para a Faculdade de Medicina da Bahia, onde concluiu o curso. Em 1905 retornou para o Rio de Janeiro, começando a trabalhar no HNA, onde foi alienista efetivo e chefe da Seção Pinel. (PAIM, op. cit., 2003, p. 107).

74 Waldemar de Almeida formou-se pela FMRJ em 1909, foi interno, assistente e depois médico da Assistência a Alienados entre $1908-1922$ e diretor do Asilo Colônia de Alienados de Vargem Alegre a partir de 1922. Entre 1915-1922 possuía consultório particular no Largo da Baronesa (SBNPML, Capa. In: Arquivos Brasileiros de Neuriatria e Psiquiatria, Rio de Janeiro, ano IV, n.1, 1922; Almanak Laemmert, 1910; 1915; 1922)

75 CERQUEIRA, op. cit., 2014, p. 79.

76 Maurício Campos de Medeiros, natural do Rio de Janeiro, formou-se em farmácia em 1903 e em 1907 concluiu o curso de medicina. Trabalhou como livre-docente das cadeiras de patologia geral na Faculdade de Medicina e de psicologia na Escola Normal do Distrito Federal. Em 1915 foi nomeado diretor-geral de Higiene do estado do Rio de Janeiro e, no ano seguinte, foi eleito para a câmara estadual fluminense. Também exerceu mandatos como deputado federal pelo estado do Rio nos períodos de 1916-1920 e 1927-1930. (Disponível em http://cpdoc.fgv.br/producao/dossies/JK/biografias/ mauricio_de_medeiros, consultado em 01/05/2015).

77 Plínio Olinto, doutor pela FMRJ em 1910, foi interno efetivo do HNA, professor de psicologia infantil do Pedagogium em 1911 e assistente do laboratório de psicologia experimental do HNA até 1915, ingressando por concurso no ano seguinte na Escola Normal, como professor de Psicologia, onde trabalhou até 1930. (CAMPOS, R. H. F. (Org.). Dicionário Biográfico da Psicologia no Brasil. Pioneiros. Rio de Janeiro: Imago Editora; Brasília: CFP, 2001. p. 256-257).

78 George Dumas (1866-1946) foi professor de psicologia experimental (1902-1937) da Faculdade de Letras da Sorbonne, em Paris, e chefe do Laboratório de Psicologia Experimental, anexo à clínica de moléstias mentais da Faculdade de Medicina da citada universidade. Foi editor do Journal de Psychologie Normale et Pathologique, em parceria com Pierre Janet. Até 1908, havia escrito na área da filosofia um trabalho sobre Aristóteles e sobre psicologia as seguintes obras: Le tristesse et la joie; Le mysticisme; Les emotions; Les deux messies positivistes - Comte et Saint Simon. (0 Paiz, 28/08/1908: 2).

79 Manoel Bomfim, assim como Maurício de Medeiros, frequentou os cursos de psicologia ministrados por Dumas e trabalhou ao seu lado no laboratório de psicologia experimental do Hospital de Sant'Anna em Paris. (LOURENÇO FILHO, op. cit., 1994, p. 309).

80 SBNPML, Boletim. In: Arquivos Brasileiros de Psiquiatria, Neurologia e Medicina Legal, Rio de Janeiro, ano IV, n. 3-4, 1908, pp.460-461.

81 SBNPML, Boletim. In: Arquivos Brasileiros de Psiquiatria, Neurologia e Medicina Legal, Rio de Janeiro, ano X, n. 1-2, 1914, p. 268.

82 Ver HERSCHMANN; KROPF; NUNES, op. cit., 1996.

83 Sobre os debates ocorridos na SBNPML a respeito da profissionalização da medicina legal ver CERQUEIRA, E. A perícia médico-legal e o ensino: dissidências e discussões na Sociedade Brasileira de Neurologia, Psiquiatria e Medicina Legal. História, Ciências, Saúde-Manguinhos, Rio de Janeiro, v. 22, n. 2, p. 641-649, 2015.

[Recebido em Agosto de 2015. Aprovado para publicação em Maio de 2016] 